\title{
The Effect of Online Protests and Firm Responses on Shareholder and Consumer Evaluation
}

\author{
Tijs van den Broek ${ }^{1}$ (D) David Langley ${ }^{2,3}$ - Tobias Hornig ${ }^{4}$
}

Received: 11 February 2016/ Accepted: 26 July 2017/Published online: 8 August 2017

(C) The Author(s) 2017. This article is an open access publication

\begin{abstract}
Protests that target firms' socially irresponsible behavior are increasingly organized via digital media. This study uses two methods to investigate the effects that online protests and mitigating firm responses have on shareholders' and consumers' evaluation. The first method is a financial analysis that includes an event study which measures the effect of online protests on the target firm's share price, as well as an investigation of the boundary effects of protest characteristics. The second method is an online experiment that assesses the effect of an online protest campaign on consumers' perception and purchase intention, as well as any mitigating effects that a firm's response may have. Contrary to recent studies suggesting that participation in online protests is only token support without any substantive effects, our results show that online protests do hurt. Firms can expect to suffer financial, reputational, and sales damage when an online protest campaign mobilizes consumers successfully. We also show that online protests are more likely to take firms by surprise than offline protests. Firms can exacerbate or reduce the damage by their response. We find that although firms may repair the damage to consumers' purchase intentions, the negative effects on a brand's image are harder to rectify.
\end{abstract}

Tijs van den Broek

t.a.vandenbroek@utwente.nl

1 Netherlands Institute for Knowledge Intensive Entrepreneurship (NIKOS), University of Twente, P.O. Box 217, 7500 AE Enschede, The Netherlands

2 TNO Netherlands Organization for Applied Scientific Research, The Hague, The Netherlands

3 Faculty of Economics and Business, University of Groningen, Groningen, The Netherlands

4 Siemens AG, Erfurt, Germany
The results have valuable implications for protest organizers and managers faced with the task of responding.

Keywords Consumer activism · Corporate social responsibility $\cdot$ Response strategies $\cdot$ Stakeholder management · Reputation - Financial impact

\section{Introduction}

Corporate social responsibility (CSR) implies that firm policies and practices exceed the narrow, technical, and legal requirements to create economic value (Davis 1973). Firms are increasingly considered as social actors that, beyond their mere economic self-interest, adhere to or even actively change norms in society (Scherer and Palazzo 2007). Within the CSR literature, scholars see firms as corporate citizens, which does not only mean that corporations need to behave like 'good citizens', but that they are responsible for protecting citizen rights (Matten and Crane 2005). Other actors in society apply ever-increasing pressure on firms to act as a corporate citizen by means of their CSR policy and practices (Matten and Crane 2005).

Consumer protests, the public display of consumers' disapproval of a firm's socially irresponsible behavior, may motivate firms to improve their corporate social responsibility (CSR) policies and practices (King 2008; King and Soule 2007; Den Hond and De Bakker 2007). An increasing body of research indeed indicates that consumer protests can severely damage such a firm's reputation (Bartley and Child 2011; King 2008; King and Soule 2007). Feedback from stakeholders who are important for the survival of the targeted firm often mediates the effect of protests on corporate decision makers (Vasi and King 2012). Activist groups thus often aim to influence 
stakeholders inside and outside the organizational boundaries, who in turn pressure the targeted firm to behave more socially responsible (Aguilera et al. 2007). Shareholders are, for example, sensitive to the negative publicity that a protest engenders and may disinvest if they expect this will affect the share price or future cash flows (Groening and Kanuri 2013; Mackey, Mackey, and Barney 2007; Vasi and King 2012). Protests may also affect consumers' image and its associated brands, and purchase intention (Krishnamurthy and Kucuk 2009).

Digital media, such as social networking sites, increasingly offer activists an efficient platform to organize such protests by exchanging information about a firms' CSR performance and uniting consumers with a negative attitude against a firm to voice their disapproval (Krishnamurthy and Kucuk 2009; Xia 2013). Consequently, digital media are important channels for communicating with targeted firms and their stakeholders about social issues (Castelló et al. 2013; De Bakker and Hellsten 2013; Palazzo and Basu 2007; Schultz et al. 2013; Whelan et al. 2013). Firms' CSR managers need to better understand how online protests affect their firms' and brands' value in order to manage unexpected situations efficiently. Online protests may require a significant change in CSR managers' stakeholder management capabilities, with the focus less on the one-way communication of CSR and more on two-way, or networked, dialog with the activist groups and their supporters (Castelló et al. 2013; Schultz et al. 2013).

While extant research demonstrates the impact of offline protests targeted at firms (Braunsberger and Buckler 2011; Chavis and Leslie 2009; Friedman 1999; Klein et al. 2004; Koku et al. 1997; Neilson 2010; Yuksel and Mryteza 2009), we know little about the effects of online protests on firm and brand value (Koku 2012), and about how firms should respond to mitigate the potential damage (Xia 2013). Although CSR managers are increasingly aware of the power of the internet to inform their stakeholders about their CSR policies and practices (Palazzo and Basu 2007), activist groups' requests are often not dealt with effectively. ${ }^{1}$ Therefore, this study investigates the impact of online protests on shareholders' and consumers' evaluation, as well as the interventions that the targeted firm undertakes when it becomes the target of a protest. Our research question is: "To what extent do online protests influence shareholders' and consumers' evaluation of the targeted firm, and how do responses from the targeted firm mitigate damage due to online protests?"

We develop a conceptual model with nine hypotheses about the effect of online protests on the evaluation of

\footnotetext{
$\overline{1}$ See, e.g., http://socialmediainfluence.com/2010/10/05/socialmedia-screw-ups-a-history/ for a list of cases.
}

shareholders and consumers, and the mitigating effects that firm responses may have on the online protest's damage. We employ two methods to test our hypotheses. First, we present a financial analysis that includes an event study ( $n=116)$ which examines the effect of online protests on the targeted firms' share price, and a regression analysis that assesses the boundary conditions of the protest characteristics. Second, we conduct an online experiment $(n=201)$ to study the effects of an online protest on consumers' image of a targeted firm, their purchase intention, and the mitigating effects of a targeted firm's response. The results of these two approaches add to our understanding of online protests' effects and provide practitioners insights into the importance of online protests and how stakeholder evaluations are influenced.

Our study contributes to CSR theory in three ways. First, our assessment of the impact of online protests contributes to the discussions on the effectiveness of low-effort protest (Den Hond and De Bakker 2007; Van Laer and Van Aelst 2010). Second, we study the effects of protests on shareholders' and consumers' evaluation, rather than the policy outcome. Following Aguilera et al. (2007)'s multilevel stakeholder framework, we show how activist groups target firms' stakeholders on an organizational level (shareholders and consumers). Last, we contribute to theory on how firms respond to protest (Eesley and Lenox 2006; King 2008; Xia 2013; Yuksel and Mryteza 2009) by examining the mitigating effects that firm responses produce.

\section{Theory}

\section{Conceptual Model and Hypotheses}

Our conceptual model is based on the organizational level of the multilevel theory of social change (Aguilera et al. 2007). This hierarchical model includes stakeholders who influence CSR on the individual level (employees), organizational level (shareholders, managers, and consumers), national level (governments), and transnational level (NGOs). The stakeholders on the organizational level are split into insider and outsider stakeholders. Insider stakeholders, such as managers and shareholders, have the most direct power over CSR decisions, as they negotiate directly in the decision-making politics within a firm. Outsider stakeholder groups, such as consumers, put pressure on the insider stakeholders by means of their voice (protest) or exit (refraining from consumption). Stakeholders on each level pressure firms to engage in CSR activities and may interact while doing so. Our study specifically examines this interaction between the (trans)national level and the organizational level. Figure 1 shows our conceptual model 


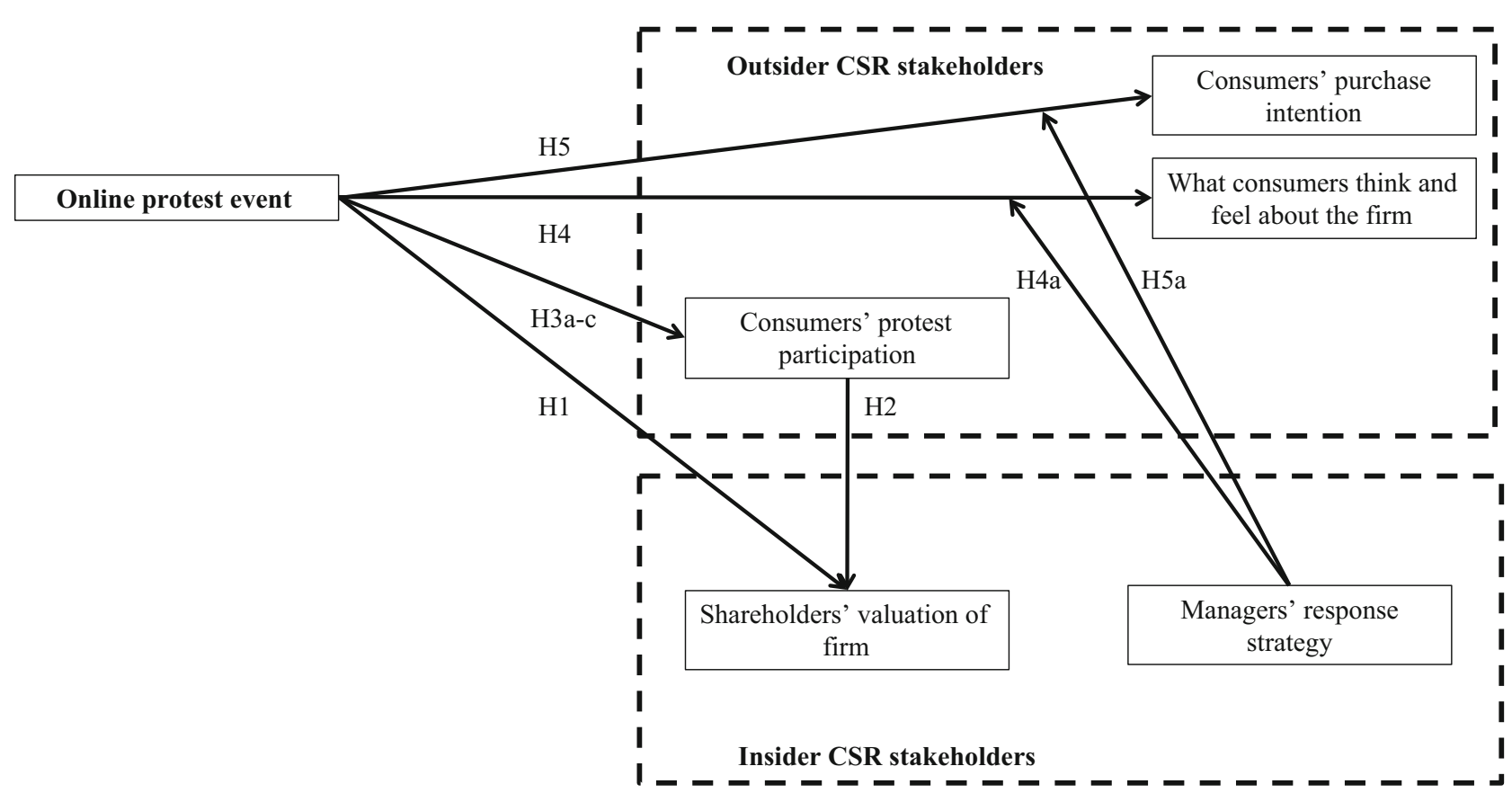

Fig. 1 Conceptual model of the effects of online protests based on Aguilera et al's (2007) multilevel framework of social change

and hypotheses. We develop the hypotheses in the paragraphs below.

\section{The Effect of Online Protests on Share Value}

Although the impact of protests on firms is difficult to measure (Bartley and Child 2011; King and Soule 2007; Vasi and King 2012), a number of studies have assessed the effect of such actions. Bartley and Child (2011) examine the effects of anti-sweatshop protests on consumer and shareholder evaluations: reputation, sales, and share prices. Their results show that protests can decrease the CSR ratings and lower the share prices. The effect of the investigated protests on sales and reputation depended, however, on the type of firm and the protest intensity. First, these protests only decreased the sales of highly specialized and recognizable firms. Second, only highly intense protests tarnished the reputation of firms with a good reputation.

Other studies focus on the effects of offline protests on a specific stakeholder. First, firms that have experienced a drop in their reputational standing are more vulnerable and are, therefore, more likely to respond positively to protesters' requests (King 2008). Second, Chavis and Leslie (2009) demonstrate that calls to boycott French wine in the USA during the war in Iraq did indeed result in significantly lower weekly sales. Third, most studies on the effects of offline protests use the financial value of the firm as the outcome variable. When stakeholder support turns into stakeholder activism, the effects on the financial value are mixed. In an event study, King and Soule (2007) demonstrate that protests influence a firm's financial performance negatively when measured as a short-term abnormal variance in the share price. In a later study, however, Vasi and King (2012) test this relation for long-term effects. In an analysis of stakeholder activism targeted at more than 200 US firms between 2004 and 2008, they find that protests did not increase the firms' perceived environmental risk and consequently did not affect their financial performance in the long term. Shareholders' perceptions of protests may mediate their effect on the targeted firms' financial value: An analysis of corporate social events which have either positive or negative effects on other stakeholders shows that shareholders may react positively to events that other stakeholders perceive as negative (Groening and Kanuri 2013).

Similarly, an online protest provides shareholders with information about a firm's possible socially irresponsible behavior, which may result in social pressure to disinvest in the targeted firm, as well as concerns about its future cash flows. We assume that shareholders update their beliefs about the future firm performance when they become aware of an online protest. It might take some time for an online protest to gain momentum before shareholders notice the protest, but from that moment onward the stock markets will reflect the shareholders' expectations regarding the future sales and profitability, with any changes in these expectations are reflected in the share prices (King and Soule 2007). 
In an event study by Koku (2012), however, no significant effect is found concerning the stock market reaction to online protests. Koku, however, questions the generalizability of his findings, and we believe there are three possible explanations for the lack of effects. First, the study was based on a small sample size $(n=63)$. Second, the protests included in the study were all calls to boycott, which require more effort from the protest participants than protests only aimed at changing consumers' attitudes. Third, individuals rather than formal protest groups, which have more resources to mobilize consumers behind their cause, initiated and organized all the protests. As such, the literature is inconclusive on whether or not protests via online channels affect the targeted share value like traditional offline protests do. In recent years, shareholders have made increasing use of online channels to gather marketrelevant information (O'Connor 2013). We therefore expect online protests to have an effect on the shareholder expectations of a targeted firm's future cash flow. Thus, adding to King and Soule's (2007) findings regarding the offline situation, we expect online protests to also negatively affect the targeted firm's share price. This leads to our first hypothesis:

H1 Online protests have a negative effect on the price of a firm.

\section{Protest Size}

Previous research identifies protest size as an important factor in changing firm behavior and as potentially having financial consequences for a targeted firm (Bartley and Child 2011; Luders 2006; Tilly 2004). Online protests which succeed in attracting large numbers of participants help activist groups draw investors' and traditional media's attention, which gives this group a powerful position with respect to the targeted firms. However, King and Soule (2007) do not find a significant relationship between protest size and share price. They indicate that their dataset is limited to protests aimed at US firms, which may bias their results, as US firms tend to be less stakeholder-centric than European firms. Online mass mobilization may draw the attention of various stakeholders, including the shareholders. Therefore, despite the mixed results to date, we expect online protests with a higher number of participants to have a stronger negative effect on a firm's share price. We thus hypothesize:

H2 Online protests with a higher number of participants have a stronger negative effect on the share price of a firm than smaller protests.

\section{Protest Characteristics}

Besides the question of whether there is an effect on the share price of a firm under attack, it is important to investigate the conditions under which such an effect occurs. Building on the above theoretical development section, we hypothesize that Eesley and Lenox's (2006) protest characteristics affect the protest size. Legitimacy refers to 'a generalized perception or assumption that the actions of an entity are desirable, proper or appropriate within some socially constructed system of norms, values, beliefs, and definitions' (Suchman 1995, p. 574). Legitimacy is a characteristic of stakeholder groups that may increase pressure on firms (Mitchell et al. 1997; Eesley and Lenox 2006). Protest organizers differ in the degree to which they are perceived as legitimate actors in society, which provides them with moral resources, such as support from consumers. As a moral authority, legitimacy may grant activist groups access to a firm's constituencies that are critical for its survival, for example, its consumers (Mitchell et al. 1997). We hypothesize that the large-scale mobilization of consumers to join an online protest campaign requires an activist group perceived as legitimate (Bennett and Segerberg 2012; Van den Broek et al. 2012). Public opinion surveys show that NGOs and public organizations to a lesser degree enjoy high levels of legitimacy (see, e.g., Edelman 2016), giving them the capability for mass mobilization, and qualifying them to represent their support as based on a CSR issue. In contrast, individuals may lack such legitimacy and are less able to mobilize large numbers of consumers than NGOs. We therefore hypothesize:

H3a The number of participants in online protests targeted at a firm depends on the legitimacy of the protest initiator.

Second, legitimacy also refers to the request made by activist groups (Eesley and Lenox 2006). As suggested by Mitchell et al.'s (1997) stakeholder theory, the cause and its solution that an activist group supports need to be perceived as legitimate. We argue that when protests are product-related and appeal predominantly to a firm's consumer base, they are more likely to appeal less to the general public than value-related issues, such as CSR issues (Swimberghe et al. 2011). We do not expect the legitimacy of activists' request to have a different effect on the online setting than it has been shown to have on offline protests. Therefore, we hypothesize:

H3b Highly legitimate protest requests relating to widely relevant value-related issues result in higher protest participation than protest requests relating to narrower product-specific issues. 
Third, we expect the urgency of the request, in other words the time frame of a protest's demand, to have an effect on consumer participation in such a protest. Given media's short attention span, consumers may prefer to participate in protests urgently demanding a change in a firm's current behavior. Eesley and Lenox (2006) do not find that a very urgent request affects firm responses, but did not assess a request's effect on participation. We thus propose the following hypothesis:

H3c Urgent protest requests calling for the cessation of the current firm behavior result in higher protest participation than protests against a firm's planned future behavior.

\section{The Effect of Online Protests on Consumers' Image}

The pressure on CSR policy and practices also depends on consumers' perceptions and behavior with respect to a firm (Chavis and Leslie 2009). First, an online protest can affect consumers by negatively affecting their attitude toward a firm. We assume that online protests aimed at highlighting and changing undesired corporate behavior have a cognitive effect on the way consumers exposed to the protest perceive such a firm. In other words, the way consumers think and feel about a targeted firm will become more negative after their exposure to protest (King and Soule 2007). Technological convenience and social connectedness are two online mechanisms that increase exposure to a protest in order to reach a large number of consumers (Kucuk and Krishnamurthy 2007). First, the technological convenience of the internet makes wide-reaching communication more affordable and easier, offering protesters an efficient structure to mobilize consumers for protests targeted at firms. Second, the social connectedness and interactivity of the internet stimulate the formation of online communities and encourage consumers to spread information about the protest. This mass interactivity enables consumers to personalize the frames that activist groups offer (Bennett and Segerberg 2012). Both the technological convenience and social connectedness help online communities reach a broader audience than is possible in an offline setting, allowing them to reach out to consumers who would normally not be exposed.

The effect of online negative information on consumer attitude has been well studied in relation to consumers sharing their negative experiences about firms, i.e., negative electronic word-of-mouth (negative eWOM) (Eberle et al. 2013). These studies find that negative eWOM has a stronger effect than positive eWOM, indicating that bad news about a firm is somehow conspicuous and influences how consumers feel about the firm in question. Similarly, we expect online protests to affect consumers' evaluation of such a firm:

H4 Exposure to an online protest negatively affects consumers' image of a firm.

\section{Moderating Effect of Firm Response on Image}

Firms are, however, not powerless when faced with an online protest and a number of options are open to them. First, a proactive communication strategy prior to a protest might prevent, or mitigate, its negative effects (McDonnell and King 2013; Yuksel and Mryteza 2009). However, proactive communication strategies that promote a firm's CSR strategy in an overly positive way may be considered as 'greenwashing' by consumers (Aji and Sutikno 2015). Greenwashing refers to the marketing of CSR practices that is seen as excessive and inappropriate self-promotion of the firm (Lyon and Montgomery 2013). Previous research suggests that greenwashing is positively related to consumer skepticism (Aji and Sutikno 2015) and negatively related to trust in environmentally friendly products (Chen and Chang 2013) and corporate legitimacy (Seele and Gatti 2015).

We assume that any negative effects after a protest will be mitigated if the targeted firm implements an adequate response strategy. Traditionally, the literature suggests that conceding to a protest signals a sense of responsibility toward consumers, which will result in positive consumer perceptions (Bradford and Garrett 1995; Conlon and Murray 1996). Subsequent research shows that this relation is not that simple (Huang 2006; Lee and Song 2010; Xia 2013). A response strategy's effectiveness depends on the firm's control over the protest issue, as well as the protest's level of evidence (Huang 2006). By conceding to a protest when consumers (other than the protesters) do not perceive the protest as justified, the protest may harm a firm's reputation (Lee and Song 2010). Furthermore, the strength of the consumer's relationship with the firm moderates the effect of an online protest (Xia 2013): The stronger consumers' relationship with a firm, the more they will tolerate a defensive response. We propose four response strategies that vary in their degree of compliance with a protest request (Bradford and Garrett 1995; Conlon and Murray 1996; Oliver 1991): (1) moving with (conceding to the protest), (2) moving toward (accommodating dialog with the protesters to justify firm behavior), (3) moving against (denying and counteracting the protest), and (4) moving away (ignoring the protest). As the two positive response strategies denote a higher responsiveness to the protesters' wishes than the latter two strategies (Xia 2013), we propose:

H4a The firm's response to a protest moderates the negative effect that an online protest has on consumers' 
perception of that firm, because the closer the firm moves toward the protest objectives, the weaker the negative effect.

\section{The Effect of Online Protests on Purchase Intention}

An online protest can affect consumers as outsider stakeholders by reducing their purchase intention, which implies that, besides the previously described exposure, online protests need to influence consumers in order for them to forego buying the targeted firm's products or services. However, evidence of this effect is limited in an online setting. Cheung and Thadani (2012) call for further research into the relationship between the online sharing of information about firms and consumer purchase intentions. Following research on the offline setting (Bartley and Child 2011), we propose:

H5 Exposure to an online protest negatively affects consumers' intention to purchase the targeted firm's products.

\section{Moderating Effect of Firm Response on Purchase Intention}

Similar to the effect on consumers' perceptions of the firm, we assume that any negative effects a protest may have on consumers' purchase intention will be mitigated if the firm implements a response strategy that is closer to the wishes of the protesters (Xia 2013):

H5a The firm's response to a protest moderates the negative effect that an online protest has on consumers' purchase intentions, because the closer the firm moves toward the protest objectives, the weaker the negative effect.

\section{Financial Analysis}

In this section, we investigate the effects of online protests targeted at firms in terms of the financial impact they have on them. Given that an online protest may change shareholders' expectations about the future firm performance (King and Soule 2007; Rappaport 1987), the onset of an online protest can be immediately translated into an adjustment of the firm's market value (Fama 1970). We assume that online protest campaigns provide capital markets with new information. First, online protests are an effective and low-cost tool that makes egregious corporate behavior publicly visible. Second, the nature of the internet offers consumers an easy and convenient way to participate in a protest against undesired corporate behavior. In turn, increased participation in an online protest targeted at firms makes a decline in sales more likely. Consequently, as more people follow the protest and revise their feelings about the attacked company, the more likely the shareholders are to adjust their risk estimations of the firm's future cash flows. Third, when an online protest reaches a certain threshold regarding its number of supporters, it can draw the attention of traditional (financial) media that shareholders follow. Consequently, new information about a firm under attack reaches the capital markets, which may lead to a reevaluation of its share price. Such mainstream attention for a protest based on purported irresponsible behavior comes at extra costs, with the total amount depending on the company's chosen response. A positive response to protests might lead to the payment of compensation, or the abandonment of lucrative business opportunities. On the other hand, if a firm does not respond, or even counterattacks, shareholders may expect such a strategy to provoke penalties, or long-term litigation, for which financial provisions will have to be made, once again affecting their future cash flow expectations.

\section{Data Description}

We built a database of 164 cases of online protest targeted at publicly traded companies during the period 1998-2011. All the cases were identified with the help of the LexisNexis media database and the Google search engine, using a combination of keywords such as online, protest, boycott, petition, and action, as well as the names of all companies currently listed on various important global stock exchanges. Additional cases were found by searching a number of popular social media platforms (Facebook, Twitter, and YouTube) for references to these companies and related protests. We excluded 48 observations with confounding events occurring before or after the event period. Confounding events are share-price-influencing events such as changes in firm's board members that occur at about the same time as the focal event, which we identified from news sources before and at the time of the protests. We used daily stock returns and Thomson Financial Datastream's and Thomson Worldscope's returns of the benchmark index to obtain a measure for the expected returns. We calculated the cumulative average abnormal returns (CAAR) to use these in the financial analysis.

\section{Event Study Results}

We applied an event study of abnormal returns to examine the value relevance of a protest for shareholders (H1). The rationale for an event study is that, given market efficiency, perfect information, and the rationality of shareholders (Fama 1991), the relevance of an event is measureable in terms of abnormal returns, i.e., a stock return that deviates 
from its expected value. Expectations about the daily returns of common stocks are usually best described by the market model (Brown and Warner 1985), which is a statistical model based on the capital asset pricing model (CAPM) and relates the return of a given stock $i$ to the return of the benchmark portfolio $m$ at time $t$ :

$E\left(R_{i t}\right)=\alpha_{i}+\beta_{i} R_{m t}$

where $E\left(R_{i t}\right)=$ expected stock return of firm $i$ on day $t$, $R_{m t}=$ returns on the market portfolio on day $t$, $\alpha_{i}, \beta_{i}=$ parameter estimates obtained from the regression of $\mathrm{R}_{\mathrm{it}}$ on $\mathrm{R}_{\mathrm{mt}}$

The problem that we try to solve by using an event study is that we do not know what would have happened in the absence of an online protest. Therefore, we construct a synthetic comparison observation based on the CAPM model. This model describes what would have happened in the absence of a protest by relating the return of a given stock to market return. The benchmark portfolio is the standard market portfolio as provided by Fama-French datasets. This is a typical approach and includes US-listed firms. There is no contamination of the market outcome by the negative news, as the model is predicted for each firm before the event, or before bad news was made known, i.e., we calculate the beta during the observation period and then subsequently use it to calculate the expected return during the event period. The difference between the actual and the expected return then defines the abnormal return. Any deviation in the realized return from the return that the model predicted is attributed to the online protest. This allows the general effect of online protests on stock value to be assessed across protests.

We use an observation period of 239 days to obtain the regression parameters of the expected return for each event, following the approach of King and Soule (2007), who examine the influence of offline protests on the financial performance of US companies in the period 1962-1990. In order to avoid the event potentially influencing the estimation, the estimation window ends 30 days prior to the event. We measure the abnormal return attributable to the protest as the difference between actual and expected return of the share of firm $i$ at time $t$ :

$A R_{i t}=R_{i t}+E\left(R_{i t}\right)=R_{i t}-\left(\hat{\alpha}_{i}+\hat{\beta}_{i} R_{m t}\right)$

Using a sample of $N$ protests, we calculate the mean effect of all the protests as the average of the abnormal returns across all the protests at time $t$ :

$A R_{t}=\frac{1}{N} \sum_{i=1}^{N} A R_{i t}$

However, it is unrealistic to only assume a significant effect on the day of the protest itself. Information about the protest might leak to shareholders in advance, or the protest may need time to disseminate its message to a wide audience (King and Soule 2007). Consequently, the observation of abnormal returns during a window pertaining to the launch of the protest is more appropriate. Hence, we aggregate daily abnormal returns during the period $\left[-t_{1}, t_{2}\right]$ into a cumulative average abnormal return:

$\operatorname{CAAR}_{\left[-t_{1}, t_{2}\right]}=\sum_{t=-t_{1}}^{t_{2}} \mathrm{AR}_{t}$

The statistical significance of the cumulative average abnormal return is tested, whereby we assume normally distributed error terms and use the following test statistic:

$Z_{\mathrm{CAAR}}=\frac{\mathrm{CAAR}_{\left[-t_{1}, t_{2}\right]}}{S_{\mathrm{CAAR}}}$

$S_{\mathrm{CAAR}}=\frac{\mathrm{CAAR}_{\left[-t_{1}, t_{2}\right]}}{\sqrt{N}} \sqrt{\frac{1}{N-1} \sum_{i-1}^{N}\left(\sum_{t=-t_{1}}^{t_{2}} \mathrm{AR}_{i t}-\mathrm{CAAR}_{\left[-t_{1}, t_{2}\right]}\right)}$

We calculate the CAAR for a range of event windows and find that a symmetric window of 11 days has the highest Z-value (-4.79), which is the most significant event window (Brown and Warner 1985). Hence, the estimation period starts five days prior to the day the online protest started and ends five days after this. We obtained a cumulative average abnormal return of $-.84 \%$, similar to King and Soule's (2007) results. Table 1 provides more details of the results.

We find a difference in the distribution of the daily average returns that has not been reported before. Whereas shareholders anticipate offline protests (King and Soule 2007; Koku et al. 1997), we find that the share value does not change abnormally prior to the online protest date, indicating that online attacks on firms are more likely to take firms (and shareholders) by surprise. The first significant negative abnormal return is found on day two, which reaches its lowest value five days after the protests started. This suggests that it takes some time before shareholders become aware of an online protest and are faced with its full impact, which may be due to the word-of-mouth diffusion process inherent in the way social media are used. We thus confirm our hypothesis (H1) and find that online protests have a negative influence on the financial value of a firm, although, in relation to the start date of the protest, this effect is later than the effect of offline protests. An online protest may give no advanced warning about the day when consumers are called to action. Such an online attack grows under the radar before reaching a critical mass. A firm suddenly becomes aware of the angry mob and is expected to respond immediately, without being given time to develop a well thought-out response strategy. This 
Table 1 Daily average return around the event data in respect of 116 online protests

\begin{tabular}{lccl}
\hline Day(s) & Cumulative average abnormal return $(\%)$ & Z-value & Frequency of negative returns $(\%)$ \\
\hline$[-5,+5]$ & -0.838 & $-4.788^{* * *}$ & 63.56 \\
-5 & 0.019 & 0.193 & 52.54 \\
-4 & 0.020 & 0.223 & 50.85 \\
-3 & -0.030 & -0.305 & 56.78 \\
-2 & 0.030 & 0.284 & 53.39 \\
-1 & -0.133 & -1.163 & 50.85 \\
0 & 0.094 & 0.989 & 50.00 \\
1 & -0.069 & -0.746 & 53.39 \\
2 & -0.223 & $-2.164 * *$ & 54.24 \\
3 & -0.058 & -0.464 & 47.46 \\
4 & -0.200 & $-1.885^{*}$ & 54.24 \\
5 & -0.287 & $-2.351^{* *}$ & 55.93 \\
\hline$n=116, * p<.1, * * p<.05, * * * p<.01$ & &
\end{tabular}

surprise effect can make online protests more threatening for firms than offline protests, because firms are generally not given advanced warning (e.g., via lobbying) and journalists may be pressured by journalists to respond quickly.

\section{Regression Results}

In order to test Hypothesis $\mathrm{H} 2$, we regressed the cumulative abnormal return during the event window on protest participation. We further included protest characteristics as defined by Eesley and Lenox (2006), namely the legitimacy of the protest organization, the legitimacy of the protest request, and the urgency of the request. Second, we controlled for the number of social media channels used, because a firm attacked from multiple fronts may suffer more harm than one attacked from a single social media platform (Castelló et al. 2013). Third, we operationalized the control variable firm size with the total sales (Eesley and Lenox 2006). The estimation equation for the cumulative abnormal returns of firm $\mathrm{j}$ during the event window for protest $\mathrm{i}$ is as follows:

$$
\begin{aligned}
\text { CAR }_{i j}= & \gamma_{0}+\gamma_{1} \text { NGO }_{i j}+\gamma_{2} \text { PubOrg }_{i j}+\gamma_{3} \text { Request }_{i j} \\
& +\gamma_{4} \text { Urgency }_{i j}+\gamma_{5} \text { Social Media }_{i j}+\gamma_{6} \text { FirmSize }_{i j} \\
& +\gamma_{7} \text { Participation }_{i j}+\eta_{i j}
\end{aligned}
$$

with $\eta \sim N\left(0, \sigma_{i j}^{2}\right)$, where

- $\mathrm{CAR}_{i j}$ : Cumulative abnormal return for firm $j$ during protest $i$.

- $\mathrm{NGO}_{i j}$ : Dummy variable taking the value 1 if protest $i$ against firm $j$ has been organized by an NGO, 0 if not PubOrg $_{i j}$ Dummy variable taking the value 1 if protest $i$ against firm $j$ has been organized by a public organization, 0 if not.
- Request $t_{i j}$ : Dummy variable taking the value 1 if the claim of protest $i$ against firm $j$ is value related, 0 if the claim of protest is product related.

- Urgency ${ }_{i j}$ : Dummy variable taking the value 1 if protest $i$ against firm $j$ relates to current firm behavior, 0 if it relates to the firm's future plans.

- SocialMedia $i j$ : Number of social media channels used by protest $i$ against firm $j$.

- FirmSize $i j$ : Total sales of parent firm $j$ attacked by protest $i$.

- Participation ${ }_{i j}$ : Number of explicit consumer actions, including online petition signatures, Facebook likes, YouTube views, etc.

- $\quad \gamma$ : Parameters to be estimated.

- $\eta, \sigma_{i j}^{2}$ : Error term and variance.

With participation as a focal driver of shareholders' evaluation of a protest, we eventually specified Eq. 8 to test our hypotheses $\mathrm{H} 3 \mathrm{a}-\mathrm{H} 3 \mathrm{c}$, i.e., the drivers for joining a protest. We used a log-log transformation to ensure that the participation rate remains positive when predicted. We additionally controlled for the capabilities and resources of the protest group and the targeted firm by means of the number of social media channels used in the protest, as well as the total sales of the firm in the year of the protest. The estimation equation is defined as follows:

$$
\begin{aligned}
\ln (\text { Participation })_{i}= & \delta_{0}+\delta_{1} \mathrm{NGO}_{i}+\delta_{2} \text { PubOrg }_{i} \\
& +\delta_{3} \text { Request }_{i}+\delta_{4} \text { Urgency }_{i} \\
& +\delta_{5} \ln \left(\text { Social Media }_{i}+\delta_{6} \text { Firm Size }_{i}\right. \\
& +\zeta_{i}
\end{aligned}
$$

with $\zeta \sim N\left(0, \sigma_{i}^{2}\right)$, where $\delta$ : Parameters to be estimated, $\zeta, \sigma_{i}^{2}$ : Error term and variance, and all other terms as previously defined. 
Table 2 Overview of means, standard deviations, and correlations

\begin{tabular}{|c|c|c|c|c|c|c|c|c|c|c|c|c|}
\hline & Variables & Mean & s.d. & 1 & 2 & 3 & 4 & 5 & 6 & 7 & 8 & 9 \\
\hline 1 & CAAR & -0.01 & 0.04 & 1 & & & & & & & & \\
\hline 2 & Participation & 60,784 & 336,277 & $0.21 \dagger$ & 1 & & & & & & & \\
\hline 3 & NGO & 0.38 & 0.49 & -0.09 & -0.09 & 1 & & & & & & \\
\hline 4 & Individual & 0.55 & 0.50 & 0.02 & 0.06 & $-0.86^{* * *}$ & 1 & & & & & \\
\hline 5 & $\begin{array}{l}\text { Public } \\
\text { Organization }\end{array}$ & 0.07 & 0.26 & 0.14 & 0.05 & $-0.22 * *$ & $-0.31 * *$ & 1 & & & & \\
\hline 6 & Request & 0.83 & 0.37 & -0.09 & 0.08 & $-0.32 * * *$ & 0.34 & -0.06 & 1 & & & \\
\hline 7 & Urgency & 0.73 & 0.44 & 0.13 & 0.09 & -0.13 & $0.08 * * *$ & 0.09 & $-0.16^{* *}$ & 1 & & \\
\hline 8 & Social media & 1.08 & 0.81 & -0.07 & 0.07 & 0.01 & -0.04 & 0.06 & -0.07 & 0.06 & 1 & \\
\hline 9 & $\begin{array}{c}\text { Firm size (in } \\
100,000 \$ \text { ) }\end{array}$ & 38,249 & 48,671 & 0.09 & 0.05 & -0.01 & 0.02 & -0.02 & 0.06 & -0.02 & -0.13 & 1 \\
\hline
\end{tabular}

$N=116, \dagger p<.1, * p<.05, * * p<.01, * * * p<.001$

Table 3 Regression coefficients of the effects of participation on cumulative abnormal returns and protest characteristics on participation

\begin{tabular}{|c|c|c|c|c|}
\hline & \multicolumn{2}{|c|}{ Model 1 (H2) } & \multicolumn{2}{|c|}{ Model $2(\mathrm{H} 3 \mathrm{a}-\mathrm{c})$} \\
\hline \multirow[t]{2}{*}{ Regression on: } & \multicolumn{2}{|c|}{ Cumulative abnormal return } & \multicolumn{2}{|c|}{ Participation } \\
\hline & \multicolumn{2}{|c|}{ Coefficient (standard error) } & \multicolumn{2}{|c|}{ Coefficient (standard error) } \\
\hline Constant & 0.000 & $(0.015)$ & 4.772 & $(0.746)^{* * *}$ \\
\hline \multicolumn{5}{|l|}{ Group legitimacy } \\
\hline Individuals & Baseline & & Baseline & \\
\hline NGOs & 0.008 & $(0.008)$ & 1.612 & $(0.521)^{* *}$ \\
\hline Public organizations & 0.026 & $(0.013)^{*}$ & 2.575 & $(0.739) * *$ \\
\hline \multicolumn{5}{|l|}{ Request legitimacy } \\
\hline Product-related claim & Baseline & & Baseline & \\
\hline Value-related claim & -0.009 & $(0.013)$ & 1.117 & $(0.488)^{*}$ \\
\hline Request urgency & 0.011 & $(0.009)$ & 0.018 & $(0.594)$ \\
\hline No. of digital channels & -0.003 & $(0.003)$ & 1.628 & $(0.573)^{*}$ \\
\hline Firm size $^{\mathrm{a}}$ & 0.000 & $(0.000)$ & 0.000 & $(0.000)^{*}$ \\
\hline Participation $^{\mathrm{a}}$ & -0.000 & $(0.000)^{* * *}$ & & \\
\hline$R^{2}$ & 0.113 & & 0.269 & \\
\hline Adj. $R^{2}$ & 0.056 & & 0.134 & \\
\hline$F$-value & $5.97 * * *$ & & $9.08 * * *$ & \\
\hline $\mathrm{N}$ & 109 & & 116 & \\
\hline
\end{tabular}

$* p<.05, * * p<.01, * * * p<.001$

${ }^{a}$ For reading convenience, these coefficients are multiplied by 100,000
Table 2 provides an overview of the descriptive statistics and bivariate correlations. Table 3 summarizes the regression results. The first column of Table 3 presents the estimation results of Eq. 7. The effective number of observation is 109 , and the explained variance is 0.113 . This is largely in line with other event studies in this field (King and Soule 2007). The $F$-value is $5.97(p<.001)$, indicating the model's high validity. Protest participation has a significant effect $\left(\delta \_7=0.000, p<.001\right)$ on the share price and, hence, confirms Hypothesis 2 . We do not find a significant relationship between firms with more sales being generally less exposed to risk $\left(\delta \_6=0.000\right.$, $p<.001)$. Last, protests organized by rival firms have a significant $\left(\delta \_2=.0260, p<0.05\right)$ effect on protest participation.

The second column of Table 3 shows the results of Eq. 8. The effective number of observation is 116 . The $R^{2}$ $(0.267)$ and the $F$-value (9.08) indicate a high goodness of fit. Except for protest urgency, all the coefficients are significant and show the expected sign. Consequently, protests organized by NGOs and other public organizations do indeed generate higher levels of participation than protests organized by individuals (respectively, $\delta_{-} 1=1.612$ and $\delta \_2=2.575$, both $p<.01$ ). Moreover, protests generate 
higher attention and reach if organized for value-related rather than product-related reasons $\left(\delta \_3=1.117, p<.05\right)$. Next, we find a significant correlation between firm size in terms of sales and protest participation $\left(\delta \_6=0.000\right.$, $p<.05)$. Further, the number of social media channels does increase an online protest's reach $\left(\delta \_5=1.628\right.$, $p<.01)$. To test the robustness of our findings, we conducted Ramsay's RESET test in Stata to check for omitted variable bias. This test was negative for both equations, which suggests that no important variables were omitted in the regression analyses. Last, we tested both equations for cohort effects, as protests take place in different years. The inclusion of the year in which an online protest took place had no significant effect on the analyses.

\section{Experimental study}

\section{Design and Sample}

The purpose of the experiment is to test the effect of an online protest on consumers' image of a firm, consumers' purchase intention, and how a firm's response to a protest mitigates these effects. The firm's response is one of the four strategies described above (Clemens and Douglas 2005; Conlon and Murray 1996; Oliver 1991), which we label moving with (i.e., compliance), moving toward (e.g., entering into a discussion), moving against (e.g., counterattack), and moving away (i.e., ignoring the protest). In order to test these effects, a one-factor between-subjects experimental design was used. The experimental factor was the attack-response condition with six levels: zero measurement, moving with, moving toward, moving against, moving away, and attack only. Moving away differs from the attack only condition, as, in the former, the participants in the experiment saw the protest web site followed by an online news item in which the targeted firm was described as not being available for comment. In the latter condition, the participants only saw the protest web site. Therefore, in the 'moving away' condition, consumers may assume the firm has ethically questionable reasons for explicitly refusing to comment on the protest or may have something to hide.

We selected milk as the consumer product at which to target an experimental protest campaign, as this is a common repeat-purchase product that does not generally elicit high consumer involvement, which could otherwise influence the results. Furthermore, we selected an animal welfare issue as the protest cause, because animal welfare is one of the most common causes in the consumer food industry. A total of 201 participants, recruited by a marketing research bureau that offered them a small financial reward for taking part, completed the study. The participants were selected on the basis that they are responsible for purchasing milk and their regular milk consumption. The sample group, of which $58 \%$ was male, was between 18 and 80 years of age $(M=50,05 ; S D=14.99)$. Only $2.5 \%$ of the participants were a vegetarian, who may have a higher than average interest in animal welfare issues, which is relevant for this experiment. The participants were sent an email that included a link to the study web site. They participated online and were randomly assigned to one of the attack-response conditions.

\section{Procedure}

The experiment was executed via an online application and started with a short introduction that indicated how long the experiment would take. Each participant was asked which milk brand helshe purchases, and in the remainder of the experiment that specific brand was used as the target of the attack. We do not control for all firm-related concepts, such as brand loyalty, because the participants indicated their preferred brand, thus limiting the variation in respect of brand loyalty. Additionally, as the participants were randomly assigned to the conditions, any differences would be averaged. Those who do not purchase milk were excluded from the study.

The procedure differed per condition. For the zero measurement, the participants had to fill out a questionnaire about the firm producing their chosen brand. In the attack only condition, the participants saw a mock web site of a well-known and generally well-respected environmental NGO with a message that the firm producing their chosen brand harms the environment. The attack was based on existing protests against the use of raw materials from palm plantations, which lead to the destruction of the rainforest. In the mock protest, the claim was that the milk producer procured cattle food containing palm kernels, thereby contributing to the destruction of rainforest, as natural forest is cleared to plant palm trees. These participants then filled out the same questionnaire as in the zero measurement condition. In the other four conditions-the four different firm response strategies - the participants saw the same attack and subsequently an online news item describing the online protest, as well as a statement from the targeted firm comprising one of the response strategies. The participants in these conditions filled out the questionnaire again. At the end of the questionnaire, all the participants received debriefing information that the protest was not real and was only for research purposes, and the firm in question's positive environmental performance was highlighted. 


\section{Measures}

\section{Independent Variables}

Manipulation: As shown above, there were six different manipulations: zero measurement vs. 'moving with' vs. 'moving toward' vs. 'moving against' vs. 'moving away' vs. 'attack only.' The four strategies were manipulated by means of an online news item. The attack was manipulated by the message on the NGO's web site. There was also a zero measurement group with no manipulation, which was the control group. The text of the manipulation is attached as an appendix.

\section{Dependent Variables}

In this study, there are four dependent variables, three relating to what consumers think and feel about the firm (attitude toward the firm, product and service quality, and environmental image) and one relating to consumers' purchase intention. First, 20 commonly used items were measured on a seven-point semantic differential scale to determine the attitude toward the firm (Aaker 1997). Some items were reversed scored to prevent bias. Confirmatory factor analysis initially showed a two-factor model in which 19 of the 20 items loaded on one factor. The item expensive/inexpensive did not load on the same factor and was omitted from the set of items. Reliability analysis showed a Cronbach's $\alpha$ of .97 for the remaining items. Second, the short form of the consumer-based corporate reputation scale was used to determine the image (Walsh et al. 2009). Two of the original five factors were used: product and service quality, and environmental image, each consisting of three items measured on a seven-point scale. The latter factor was adapted to remove items relating to social, rather than environmental, responsibility, because our experimental design included a protest attack based on environmental grounds. We checked the scale using a factor analysis which identified both factors with reliability $\alpha$ of .85 and .83. Last, consumers' purchase intention was measured with one seven-point item ascertaining the extent to which the participants were sure that they would buy the chosen product if they were in a supermarket and needed milk.

\section{Control Variables}

The general willingness of consumers to take part in protests was controlled for by measuring the trait action willingness, by asking if they had joined an anti-firm protest during the previous year (with multiple answer options, as well as a 'yes, other...' option). These data were transformed into a dichotomous variable for the analysis.

\section{Results}

A manipulation check $(n=70)$, using items adapted from Clemens and Douglas (2005), showed that consumers' perception of each response strategy differed significantly: moving with $\left(F=30.88, p<.01\right.$, partial $\left.\eta^{2}=.58\right)$, moving toward $\left(F=18.03, p<.01\right.$, partial $\left.\eta^{2}=.45\right)$, moving against $\left(F=4.31, p=.01\right.$, partial $\left.\eta^{2}=.20\right)$, and moving away $\left(F=3.98, p=.01\right.$, partial $\left.\eta^{2}=.15\right)$. All manipulations passed Levene's test for homogeneity $(p<.1)$. We separated the manipulation from the main experiment to avoid endogeneity.

Examining the results of the main experiment, an ANOVA shows a main effect of the experimental condition on the participants' attitude toward the firm $\left(F(5191)=7.18, p<.001\right.$, partial $\left.\eta^{2}=.16\right)$, thus confirming Hypothesis H4. A Tukey post hoc analysis shows significant contrasts between the zero measurement and all the other levels of the condition, signifying that all the manipulations had a negative effect on consumers' attitude toward the firm. Furthermore, the difference between the attack and moving away conditions showed significance, whereby the moving away strategy resulted in an even worse attitude toward the firm than the attack only condition. This result shows that no matter how the firm responds, the negative effect of the protest on consumers' attitude toward the firm remains. Consequently, Hypothesis $4 \mathrm{a}$ is not supported. On the contrary, when a firm moves away by explicitly refusing to comment on the protest, the negative effect of the protest is exacerbated. The control variable, the trait action willingness, shows no significance (main effect $\quad(F(1191)=2.309, \quad p=.130, \quad$ partial $\left.\eta^{2}=.012\right) \quad$ or interaction effect $\quad(F(5191)=.661$, $p=.654$, partial $\left.\eta^{2}=.017\right)$, indicating that previous involvement in protests does not affect attitude toward the firm.

In respect of the effects of the protest campaign on the two image constructs (product and service quality, and environmental image), a MANOVA shows a main effect of the experimental condition $(F(15,569)=2.40, p<.01$, partial $\left.\eta^{2}=.06\right)$. Once again, no significant results are found for the control variable and the trait action willingness. The univariate results show that the experimental condition has a significant effect on the firm image regarding quality $(F(5193)=4.41, \quad p<.01, \quad$ partial $\left.\eta^{2}=.10\right)$ and environment $(F(5193)=5.81, p<.001$, partial $\eta^{2}=.11$ ). In respect of the firm image concerning product and service quality, the contrasts between the strategies moving away and moving toward, as well as the zero measurement, are significant. The moving away strategy results in a more negative image concerning the quality than the moving toward strategy and the zero 
measurement; this is a similar result to that described above regarding the attitude toward the firm. In respect of the firm image concerning the environment, the contrasts between the zero measurement and moving with, moving against, moving away, and the attack only condition are significant, as is the contrast between moving away and moving toward conditions. With the exception of moving toward, all the conditions have a more negative effect on the image concerning the environment than the zero measurement has. Furthermore, moving away also has a more negative effect on the environmental image than moving toward has. Together, these results support Hypothesis H4, showing that online protests harm consumers' image of a firm. Nevertheless, they do not firmly support Hypothesis H4a, as the firm's response does not mitigate this negative effect. Again, however, the effect of the firm response differs: If the firm moves away from the protest by explicitly refusing to comment on it, the negative effect of the protest also increases.

Looking at the effects of the online protest campaign on the participants' purchase intention, we find support for Hypothesis H5. The ANOVA shows a significant main effect of the experimental condition $(F(5193)=3.35$, $p<.01$, partial $\eta^{2}=.08$ ), showing that respondents exposed to the protest were less likely to purchase the product than the control group. A Tukey post hoc analysis showed significant differences between the zero measurement and the moving away strategy, the moving against strategy, and the attack only condition (see Table 3 ). This is wholly in line with Hypothesis H5a: If the firm moves with the protest by complying with its request, or moves toward it by entering into a discussion, the negative effect of the protest on consumers' purchase intentions is attenuated. In this case, we also found that the control variable and the trait action willingness have an effect on the purchase intention $(F(1193)=4.57, \quad p<.05, \quad$ partial $\left.\eta^{2}=.02\right)$. Those participants who had joined some kind of action during the previous year had a lower purchase intention $(M=3.10, S D=1.79)$ than those without the trait action willingness $(M=3.95, S D=2.02)$.

\section{Discussion}

In this paper, we examined the effects of online protests on the stakeholder evaluations of the targeted firm. Instead of assessing the impact of protests on a single performance indicator, we studied the impact of protests on both shareholders and consumers. Additionally, we explored the boundary conditions of protest characteristics and assessed the mitigating effects of firm responses. Empirically, we focused on online protests targeted at firms that use digital media, such as social media, and we propose that such protests would negatively influence shareholders' and consumers' evaluation of the firm. We found that online protests do affect these primary stakeholders. Firms, however, are not powerless when attacked. This study makes a further contribution by assessing the effects of the firm's response to the protest and whether certain response strategies mitigate or exacerbate the effects of an online protest.

\section{Summary of Findings and Scientific Implications}

The results of this study show that low-effort participation in protests, called 'slacktivism' (Kristofferson et al. 2014), can also function as a meaningful form of protest support. Even though individual contributions do not require a significant effort or cost, their combined clicks add to the critical mass of the protest, attracting the attention of the targeted firm and the press. Owing to the nature of online campaigns, the sum of many small contributions by online slacktivists, which are visible to all, may be more than efforts of a relatively small core group of activists. In this study of the effect of online protests on firms' financial value, we find protests affect shareholders' expectations, indicated by a drop in share price $(\mathrm{H} 1)$. This finding is in line with earlier event studies on the effect of offline protests on financial value (Bartley and Child 2011; King and Soule 2007; Vasi and King 2012) and deviates from Koku's (2012) tentative conclusion that online protests may not affect firm value. Again, all observations with confounding activity that could also have affected the share price were removed from the sample. The time it takes for online protests to influence firm value in this way is an important factor that differs from offline protests. Online protests may take firms and markets by surprise. The event study shows that protests have no effect on a firm's value prior to the date the online protest is launched. Shareholders may be unaware of a protest before the launch, as the related information needs some time to diffuse throughout the online community. Added to this, the full reach of a protest and its ability to mobilize a large number of supporters are often far from clear at the outset. Our findings suggest that there is either a delay before shareholders become aware of a protest, or that they postpone their reaction to see whether the protest grows.

The regression analysis shows that the size of the protest participation influences the financial value of the targeted firm negatively (H2). As a contribution to earlier mixed findings regarding the effect of protest size on the firm value (King and Soule 2007; Luders 2006), we show that consumer participation in an online protest is an antecedent of the effect that a protest has on firms' financial value. Furthermore, we explore Eesley and Lenox's (2006) boundary conditions $(\mathrm{H} 3 \mathrm{a}-\mathrm{c})$ to explain participation in 
online protests. Protest legitimacy and request legitimacy do increase the size of a protest in terms of participation. Despite optimistic claims about the democratizing effect of digital media (Bennett and Segerberg 2012), our findings show that NGOs and public organizations can still mobilize protest participants more efficiently than individuals. Our findings regarding the urgency of the request that the protest organizers make are in line with those of Eesley and Lenox (2006) regarding the offline situation, but does not support our Hypothesis H3c, as the request urgency did not lead to an increase in the protest participation in our study. This means that when protests have a specific deadline for the targeted firm this does not increase potential participants' motivation to join the protest.

In support of our fourth hypothesis (H4) in the experimental study, we find that exposure to an online protest campaign does indeed negatively affect how consumers perceive a firm. Based on consumer evaluations in response to four firm response strategies, we find partial support for Hypothesis H4a, which posits that the closer a firm moves toward the wishes of a protest, the weaker this negative effect. However, none of a firm's response strategies can prevent damage to its reputation; even if it were to fully comply with the request of the activist group, this would still damage consumers' evaluations of it. This finding seems to modify the earlier confirmation that a prosocial communication strategy following a protest might prevent, or mitigate, a protest's negative effects (Bradford and Garrett 1995; Conlon and Murray 1996; Yuksel and Mryteza 2009). While a firm's reputation is damaged no matter what response strategy it adopts, our results show that a firm can exacerbate the problem if it adopts a 'moving away' strategy and explicitly refuses to comment on the protest. In this case, consumers' attitude toward such a firm becomes even more negative. In addition, we have found that the 'moving away' strategy has a negative effect on consumers' evaluations of the quality of a firm's products and that all response strategies, other than complying, have a negative effect in terms of the firm's environmental image.

We also find that, in line with $\mathrm{H} 5$, an online protest affects consumers' actions. After being exposed to an online protest, consumers are less likely to buy the relevant firm's products. This result follows Cheung and Thadani's (2012) call for research on the link between the electronic sharing of information about brands and purchase intention. Furthermore, we find that the two response strategies through which a firm moves closer to the wishes of the protest, thus moving with, i.e., complying with the request, and moving toward, i.e., engaging in a dialog with the community, do mitigate the damage to sales that a protest inflicts (supporting H5a). When a company does not respond, or reacts with a counter-attack strategy, consumers' intention to purchase that firm's products remains damaged (H5a). In this instance, this effect is even stronger for consumers with a history of participating in similar protests. This finding confirms that a prosocial communication strategy following a protest can prevent, or mitigate, a protest's negative effects by signaling a sense of responsibility for consumers (Bradford and Garrett 1995; Conlon and Murray 1996).

Our findings contribute to CSR literature in three ways. First, our findings combine earlier studies on the effect of protests on shareholder evaluation (Bartley and Child 2011; King 2008; King and Soule 2007; Vasi and King 2012) and consumer evaluation (Bradford and Garrett 1995; Conlon and Murray 1996; Huang 2006; Lee and Song 2010; Xia 2013). This combination of insider and outsider CSR stakeholders' evaluation is important, as shareholders tend to pressure firms on the basis of short term instrumental motives, while consumers may find ethical motives more important (Aguilera et al. 2007; Mackey et al. 2007). This means that firms face the dilemma of needing to balance their response to their stakeholders with potentially conflicting interests. Second, we study the dynamics between insider and outsider stakeholders and the inter-level relation between activist groups and consumers. Last, we contribute to the ongoing discussion on the use of digital media, such as social media, to engage consumers in CSR from both activist groups' and firms' perspective (Castelló et al. 2013; Eberle et al. 2013; Lyon and Montgomery 2013; Palazzo and Basu 2007; Schultz et al. 2013; Whelan et al. 2013).

\section{Practical Implications}

Our research provides activist groups with insights into how to improve their chances of influencing firm behavior. Furthermore, we provide commercial managers with useful results that can help them optimize their response when they become the focus of an online protest. New strategies and tactics for conflicts played out on the internet are continually being discovered and improved (Whelan et al. 2013). We specifically contribute four practically applicable findings for protest organizers. First, we confirm that online protests can be worthwhile. They can affect firms by changing the mindset of consumers to view the targeted firm in a less positive light, and they can influence consumers' purchase intentions and can also decrease the firm's share value. Second, our findings suggest that cooperative activist groups may provide firms with an exit strategy by helping them enter into a discussion to find a mutually agreeable solution (Kneip 2013). Our experimental findings suggest that a win-win solution is possible, while our event study findings suggest that activists have a window of opportunity during which the firm is acutely 
aware of the market's perception of its future risk. Third, we suggest that protest organizers need to make good use of social media channels to mobilize the masses, as this gives them power in the new online situation. Finally, the knowledge that the targeted firms are less able to predict online protests can add an element of surprise to protests.

For managers faced with protests from external stakeholders, our first finding is that they should prevent protests whenever possible. We have shown that online protests affect a firm negatively in a number of ways, in some ways regardless of its response. In our experimental study, we show that even a well-known firm suffers if it is a target of an online protest campaign. Our results suggest that doing nothing is the worst possible response, as this exacerbates the harm done by the online protest. Second, managers should invest in the development of a proactive online stakeholder strategy that helps managers enter into a discussion with consumer communities and concerned groups. Third, managers should undergo training in response strategies. Since online protests are highly likely to take a firm by surprise, there is no time for lengthy discussions or response optimization at the onset of a crisis. Managers at all levels of the organization need to know in advance how to approach an online discussion with protesters.

\section{Limitations and Future Research}

In addition to our findings, we highlight a number of our study's limitations that present opportunities for future research. First, the relationship between the effort protest supporters make and the protest's effect on the target firm is a yet to be tested. Kristofferson et al. (2014), for example, discuss the difference between token support and meaningful support, whereby meaningful support is postulated as requiring a significant effort from a participant and as a prerequisite for bringing about change. A second limitation is the conceptualization of firm responses (Oliver 1991). There are, however, many other dimensions of firm responses, such as whether firms communicate their response to individual consumers or to the public at large. Future research may examine impression management (McDonnell and King 2013) and greenwashing effects in relation to firm response strategies (Lyon and Montgomery 2013; Seele and Gatti 2015). A third limitation is the access to data on the impact of protests on firms and on the strategies they have employed. We have therefore chosen to assess a wide range of cases, whereby we were unable to delve into each case in great depth. In-depth case studies, such as process studies, would complement our quantitative study. We urge researchers to study how corporate decision makers are influenced on an individual level, and how changes in their perception result in a response to protest. A fourth limitation is the inability of our approach to capture the full richness of online protests. Event studies assume that all other factors remain equal and hence may overemphasize the effects of recent events, while not accounting for long-term effects (the ceteris paribus bias). Hence, we should be careful with strong causal claims. A fifth limitation of our study is that we do not assess multiple rounds of protests and responses. Future research may study multiple protest cycles and subsequent firm responses. Last, our study assessed the short-term effects of online protests. Future research may focus on the long-term effects, such as organizational stigmas perceived by stakeholders.

Acknowledgements We would like to express our thanks for the assistance we received during the data collection from Anita Lieverdink and Gijs Hendrix, and thank Michel Ehrenhard for his useful feedback.

Funding Funding was provied by the Dutch Ministry of Economic Affairs.

Open Access This article is distributed under the terms of the Creative Commons Attribution 4.0 International License (http://crea tivecommons.org/licenses/by/4.0/), which permits unrestricted use, distribution, and reproduction in any medium, provided you give appropriate credit to the original author(s) and the source, provide a link to the Creative Commons license, and indicate if changes were made.

\section{References}

Aaker, J. L. (1997). Dimensions of brand personality. Journal of Marketing Research, 34(3), 347-356.

Aguilera, R. V., Rupp, D. E., Williams, C. A., \& Ganapathi, J. (2007). Putting the $\mathrm{S}$ back in corporate social responsibility: A multilevel theory of social change in organizations. Academy of Management Review, 32(3), 836-863.

Aji, H. M., \& Sutikno, B. (2015). The extended consequence of greenwashing: Perceived consumer skepticism. International Journal of Business and Information, 10(4), 433.

Bartley, T., \& Child, C. (2011). Movements, markets and fields: The effects of -anti-sweatshop campaigns on U.S. firms, 1993-2000. Social Forces, 90(2), 425-451.

Bennett, W. L., \& Segerberg, A. (2012). The logic of connective action. Information, Communication \& Society, 15(5), 739-768.

Bradford, J., \& Garrett, D. (1995). The effectiveness of corporate communicative responses to accusations of unethical behavior. Journal of Business Ethics, 14(11), 875-892.

Braunsberger, K., \& Buckler, B. (2011). What motivates consumers to participate in boycotts: Lessons from the ongoing Canadian seafood boycott. Journal of Business Research, 64(1), 96-102.

Brown, S. J., \& Warner, J. B. (1985). Using daily stock returns: The case of event studies. Journal of Financial Economics, 14(1), $3-31$.

Castelló, I., Morsing, M., \& Schultz, F. (2013). Communicative dynamics and the polyphony of corporate social responsibility in the network society. Journal of Business Ethics, 118(4), 683-694.

Chavis, L., \& Leslie, P. (2009). Consumer boycotts: The impact of the Iraq war on French wine sales in the US. Quantitative marketing and Economics, 7(1), 37-67. 
Chen, Y. S., \& Chang, C. H. (2013). Greenwash and green trust: The mediation effects of green consumer confusion and green perceived risk. Journal of Business Ethics, 114(3), 489-500.

Cheung, C. M. K., \& Thadani, D. R. (2012). The impact of electronic word-of-mouth communication: A literature analysis and integrative model. Decision Support Systems, 54(1), 461-470.

Clemens, B. W., \& Douglas, T. J. (2005). Understanding strategic responses to institutional pressures. Journal of Business Research, 58(9), 1205-1213.

Conlon, D. E., \& Murray, N. M. (1996). Customer perceptions of corporate responses to product complaints: The role of explanations. Academy of Management Journal, 39(4), 1040-1056.

Davis, K. (1973). The case for and against business assumption of social responsibilities. Academy of Management Journal, 16(2), 312-322.

De Bakker, F. G. A., \& Hellsten, I. (2013). Capturing online presence: Hyperlinks and semantic networks in activist group websites on corporate social responsibility. Journal of Business Ethics, 118(4), 807-823.

Den Hond, F., \& De Bakker, F. G. A. (2007). Ideologically motivated activism: How activist groups influence corporate social change activities. Academy of Management Review, 32(3), 901-924.

Eberle, D., Berens, G., \& Li, T. (2013). The impact of interactive corporate social responsibility communication on corporate reputation. Journal of Business Ethics, 118(4), 731-746.

Edelman (2016). Edelman Trust Barometer 2016: Executive Summary. Edelman

Eesley, C., \& Lenox, M. J. (2006). Firm responses to secondary stakeholder action. Strategic Management Journal, 27(8), 765-781.

Fama, E. F. (1970). Efficient capital markets: A review of theory and empirical work. Journal of Finance, 25(2), 383-417.

Fama, E. F. (1991). Efficient capital markets: II. Journal of Finance, 46(5), 1575-1617.

Fama, E. F., \& French, K. R. (1992). The cross-section of expected stock returns. The Journal of Finance, 47(2), 427-465.

Friedman, M. (1999). Consumer boycotts: Effecting change through the marketplace and the media. New York: Routledge.

Groening, C., \& Kanuri, V. K. (2013). Investor reaction to positive and negative corporate social events. Journal of Business Research, 66(10), 1852-1860.

Huang, Y.-H. (2006). Crisis situations, communication strategies, and media coverage: A multicase study revisiting the communicative response model. Communication Research, 33(3), 180-205.

King, B. G. (2008). A political mediation model of corporate response to social movement activism. Administrative Science Quarterly, 53(3), 395-421.

King, B. G., \& Soule, S. A. (2007). Social movements as extrainstitutional entrepreneurs: The effect of protests on stock price returns. Administrative Science Quarterly, 52(3), 413-442.

Klein, J. G., Smith, N. G., \& John, A. (2004). Why we boycott: Consumer motivations for boycott participation. Journal of Marketing, 68(2), 92-109.

Kneip, V. (2013). Protest campaigns and corporations: Cooperative conflicts? Journal of Business Ethics, 118(1), 189-202.

Koku, P. S. (2012). On the effectiveness of consumer boycotts organized through the internet: The market model. Journal of Services Marketing, 26(1), 20-26.

Koku, P. S., Akhigbe, A., \& Springer, T. M. (1997). The financial impact of boycotts and threats of boycott. Journal of Business Research, 40(1), 15-20.

Krishnamurthy, S., \& Kucuk, S. U. (2009). Anti-branding on the internet. Journal of Business Research, 62(11), 1119-1126.

Kristofferson, K., White, K., \& Peloza, J. (2014). The nature of slacktivism: How the social observability of an initial act of token support affects subsequent prosocial action. Journal of Consumer Research, 40(6), 1149-1166.

Kucuk, S. U., \& Krishnamurthy, S. (2007). An analysis of consumer power on the Internet. Technovation, 27(1-2), 47-56.

Lee, Y. L., \& Song, S. (2010). An empirical investigation of electronic word-of-mouth: Informational motive and corporate response strategy. Computers in Human Behavior, 26(5), 1073-1080.

Luders, J. (2006). The Economics of movement success: Business responses to civil rights mobilization. American Journal of Sociology, 111(4), 963-998.

Lyon, T. P., \& Montgomery, A. W. (2013). Tweetjacked: The impact of social media on corporate greenwash. Journal of Business Ethics, 118(4), 747-757.

Mackey, A., Mackey, T. B., \& Barney, J. B. (2007). Corporate social responsibility and firm performance: Investor preferences and corporate strategies. Academy of Management Review, 32(3), $817-835$

Matten, D., \& Crane, A. (2005). Corporate citizenship: Toward an extended theoretical conceptualization. Academy of Management Review, 30(1), 166-179.

McDonnell, M.-H., \& King, B. (2013). Keeping up appearances: Reputational threat and impression management after social movement boycotts. Administrative Science Quarterly, 58(3), 387-419.

Mitchell, R. K., Agle, B. R., \& Wood, D. J. (1997). Toward a theory of stakeholder identification and salience: Defining the principle of who and what really counts. Academy of Management Review, $22(4), 853-886$.

Neilson, L. A. (2010). Boycott or buycott? Understanding political consumerism. Journal of Consumer Behaviour, 9(3), 214-227.

O'Connor, L. G. (2013). Investors' information sharing and use in virtual communities. Journal of the American Society for Information Science and Technology, 64(1), 36-47.

Oliver, C. (1991). Strategic responses to institutional processes. Academy of Management Review, 18(1), 145-179.

Palazzo, G., \& Basu, K. (2007). The ethical backlash of corporate branding. Journal of Business Ethics, 73(4), 333-346.

Rappaport, A. (1987). Stock market signals to managers. Harvard Business Review, 65(6), 57-62.

Scherer, A. G., \& Palazzo, G. (2007). Toward a political conception of corporate responsibility: Business and society seen from a Habermasian perspective. Academy of Management Review, 32(4), 1096-1120.

Schultz, F., Castelló, I., \& Morsing, M. (2013). The construction of corporate social responsibility in network societies: A communication view. Journal of Business Ethics, 115(4), 681-692.

Seele, P., \& Gatti, L. (2015). Greenwashing revisited. In search of a typology and accusation-based definition incorporating legitimacy strategies. Business Strategy and the Environment, 26, $239-252$

Suchman, M. C. (1995). Managing legitimacy: Strategic and institutional approaches. Academy of Management Review, 20(3), 571-610.

Swimberghe, K., Flurry, L. A., \& Parker, J. M. (2011). Consumer religiosity: Consequences for consumer activism in the United States. Journal of Business Ethics, 103(3), 453-467.

Tilly, C. (2004). Social movements. Boulder: Paradigm.

Van den Broek, T. A., Ehrenhard, M. L., Langley, D. J., \& Groen, A. J. (2012). Dotcauses for sustainability: Combining activism and entrepreneurship. Journal of Public Affairs, 12(3), 214-223.

Van Laer, J., \& Van Aelst, P. (2010). Internet and social movement action repertoires: Opportunities and limitations. Information, Communication and Society, 13(8), 1146-1171.

Vasi, I. B., \& King, B. G. (2012). Social movements, risk perceptions, and economic outcomes: The effect of primary and secondary 
stakeholder activism on firms' perceived environmental risk and financial performance. American Sociological Review, 77(4), 573-596.

Walsh, G., Beatty, S. E., \& Shiu, E. M. K. (2009). The customerbased corporate reputation scale: Replication and short form. Journal of Business Research, 62(10), 924-930.

Whelan, G., Moon, J., \& Grant, B. (2013). Corporations and citizenship arenas in the age of social media. Journal of Business Ethics, 118(4), 777-790.
Xia, L. (2013). Effects of companies' responses to consumer criticism in social media. International Journal of Electronic Commerce, 17(4), 73-100.

Yuksel, U., \& Mryteza, V. (2009). An evaluation of strategic responses to consumer boycotts. Journal of Business Research, 62(2), 248-259. 